\title{
Cost and effectiveness of the California triple marker prenatal screening program
}

George C. Cunningham, MD, MPH and D. Gwynne Tompkinson, PhD

\begin{abstract}
Purpose: To report the utilization of services offered and pregnancy outcomes for a unique statewide prenatal triple marker screening program and to present a cost-benefit analysis. A state population of 32 million with considerable ethnic and age distribution and with a wide variety of delivery systems providing prenatal care was considered. The entire pregnant population who appeared for care before 20 weeks gestation, approximately one-half million per year during the years of 1995 to 1997, was included in the study. Methods: Mandatory offering of serum testing, using alpha-fetoprotein from 1986 to 1995, and the addition of human chorionic gonadotropin and unconjugated estriol in 1995, with systematic follow-up of serum screen positives with ultrasound and amniocentesis. This study collected and analyzed the program data and reports of outcomes and collected similar information from the birth defects registry. Results: Triple marker serum screening was accepted by $67.4 \%$ of the women eligible and yielded an initial positive rate of $7.3 \%$. More than $90 \%$ of the initially screen positive pregnancies were seen at a prenatal diagnostic center. After correction of gestational age, $71.3 \%$ had amniocentesis. The overall amniocentesis rate among women screened was $2.6 \%$. The Program's detection rate was predicted to be $85 \%$ for neural tube defects, and, based on Monte Carlo modeling, was theoretically calculated to be $62 \%$ for Down syndrome. In practice, detection rates were $75 \%$ for neural tube defects and $41 \%$ for Down syndrome due to lower than expected amniocentesis acceptance rate. Nevertheless, at a $5 \%$ discount rate, the screening program was cost beneficial at a ratio of 2.69:1. The cost per case detected was $\$ 35,365$ and per case prevented was $\$ 110,741$. Conclusion: It is possible to implement a cost-effective population-based screening in compliance with quality standards in a diverse ethnic population with a variety of health-care providers. Triple marker screening in the second trimester is a cost beneficial program even if utilization of all services is less than ideal. Genetics in Medicine,
\end{abstract} 1999:1(5):200-207.

Key Words: Screening, cost/benefit, prevention, birth defects, prenatal care

With the explosion of knowledge in the field of genetics, public health agencies are beginning to discuss and debate the implications with respect to the traditional areas of public health responsibility. Public health agencies must now consider whether new models and mechanisms are needed to keep public health as an active, responsible participant. ${ }^{1-3}$ This article describes a model adopted in California for constructively addressing this challenge and an assessment of the degree to which it has achieved its objectives.

\section{HISTORY OF MSAFP SCREENING}

Maternal serum alpha-fetoprotein (MSAFP) screening became a technical possibility when Brock ${ }^{4}$ reported elevated AFP in maternal serum from pregnancies with fetuses affected with neural tube defects (NTD). The screening characteristics of MSAFP were developed in a large collaborative study in the United

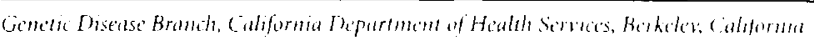

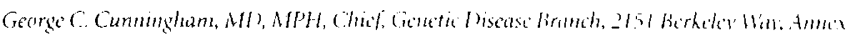
4. Berkiclen CA 44704 .

Reciberl: March 17. 1999

Acceptct: /unc 23. 1999
Kingdom, published in $1977 ;^{5}$ shortly thereafter, screening of the pregnant population became increasingly a standard of practice in the United Kingdom. However, due to the fact that in the United States the Food and Drug Administration had no previous experience with screening applications of this nature, and in part due to the opposition of antichoice groups, the first licenses for marketing test kits in the United States were not granted until 1984. In 1986 California initiated its statewide program based on a unique public/private partnership model.

\section{PROGRAM DESCRIPTION}

California's program was designed to meet or exceed the guidelines for MSAFP screening published by the American Society of Human Genetics (ASHG) and other professional groups. ${ }^{6-8}$ The program was authorized by the State Legislature and implemented by the State Department of Health Services regulations. The patient flow is schematically summarized in Figure 1.

The law requires that all women seen before the 140th day (20th week) of gestation be provided with a state-prepared booklet describing the risks and benefits of MSAFP screening. The woman's signature on the consent/refusal form contained in the booklet indicates whether they choose or decline to participate. 
The Program distributes all forms, tubes, mailing containers, and a provider participation booklet free of charge to all of the almost 7,000 prenatal care providers in California.

Blood specimens are sent to one of eight regionalized private laboratories, under contract with the Program, which conduct the automated assay in accordance with a uniform protocol and under strict quality control of the State Genetic Disease Laboratory. Results are transmitted electronically to the Genetic Disease Branch computer in Berkeley, CA, which interprets them and prints out and mails reports to clinicians.

Screen positive test results and other test results needing some sort of follow-up action are electronically transmitted to 14 stateapproved coordinator offices regionally located at area genetic centers. These area genetic centers may be publicly or privately funded, and are under contract with the State to provide followup services. Follow-up consists of telephoning the clinician's office, and confirming the patient/pregnancy information used in test interpretation. Coordinators arrange for state-authorized follow-up at 1 of 29 prenatal diagnostic centers (PDC), with 90 satellite sites that meet State criteria for counseling, ultrasound, amniocentesis, karyotyping, and amniotic fluid analysis of AFP and acetylcholinesterase ( $\mathrm{AChE}$ ). The approved centers are reimbursed by the State on an agreed upon fee for service schedule (Table 1).

The original one-time only, all-inclusive participation fee is billed, after testing is complete, to the patient or insurance carrier, but this has been increased over time (Table 2). The $\$ 115$ fee represents a change to triple marker screening. This increase in fees is an important point because the Program is not a taxsupported service, and the fee may be regarded as a measure of willingness to pay. Despite increases in fees, the participation rate continues to increase.

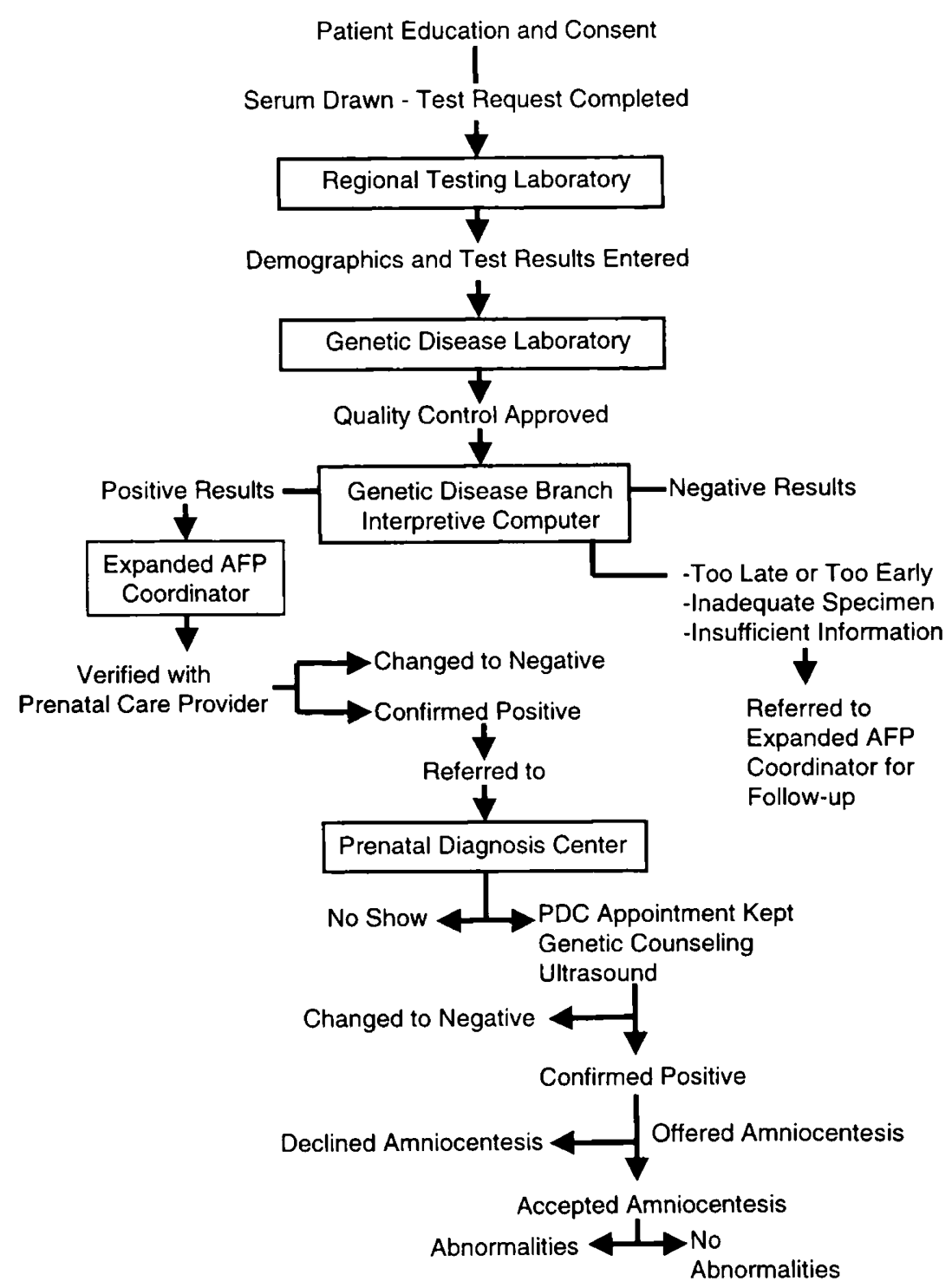

Fig. 1 Patient flow through the screening process in the California Expanded AFP Program. 
Table 1

California MSAFP program reimbursements

\begin{tabular}{lr}
\hline Genetic counseling & $\$ 110.00$ \\
Ultrasound & $\$ 175.00$ \\
Amniocentesis & $\$ 125.00$ \\
Karyotyping & $\$ 385.00$ \\
AF-AFP and AF-AChE & $\$ 40.00$ \\
\hline
\end{tabular}

Utilization of the original MSAFP screening program steadily increased from $41 \%$ in 1986 to $63 \%$ of eligibles in 1994 (Table 3). From 1986 to $1994,2,422,881$ women elected to participate in this single marker (AFP) screening program, and more than 3,000 birth defects (neural tube defects, abdominal wall defects, and significant chromosome anomalies) were detected. The approved PDCs provided a substantial volume of services during this period, performing 23,463 ultrasounds and 12,634 amniocenteses.

\section{Conversion from single marker to triple marker screening}

In mid-1995, the Program implemented triple marker screening. An automated analytical system, AutoDelfia (EG\&G Wallac Oy, Turku, Finland); was selected to measure intact human chorionic gonadotropin (hCG), unconjugated estriol $\left(\mathrm{UE}_{3}\right.$ ), and AFP. At the central computer, laboratory assay results are combined with the patient/pregnancy information. The median value for each analyte at each gestational day is determined. The woman's analyte values are then converted to multiples of the analyte median (MoM) for gestational age in days, and adjustments for maternal weight and race are applied. Risks for Down syndrome are calculated using a probabilistic likelihood ratio algorithm ${ }^{9}$ based on maternal age and the three analyte MoMs. The Expanded
Table 2

California MSAFP program participation fee

\begin{tabular}{lll}
\hline August & 1986 & $\$ 40.00$ \\
September & 1988 & $\$ 49.00$ \\
October & 1991 & $\$ 53.00$ \\
November & 1992 & $\$ 55.00$ \\
January & 1995 & $\$ 57.00$ \\
July & 1995 & $\$ 115.00$ \\
March & 1998 & $\$ 105.00$ \\
\hline
\end{tabular}

AFP Program is treated as three screening programs. An MSAFP MoM of 2.5 or greater in a singleton pregnancy is screen positive for neural tube or abdominal wall defects (AWD). A term risk of 1:250 or greater, now expressed as a mid-trimester risk of 1:190 or greater) is screen positive for Down syndrome. Screen positive for trisomy 18 initially required values $<0.60 \mathrm{MoM}$ for hCG, $<0.75 \mathrm{MoM}$ for AFP, and $<0.55 \mathrm{MoM}$ for $\mathrm{UE}_{3}$. The Program now uses a mid-trimester risk of 1:100 or greater as screen positive for trisomy 18 , calculated by a probability algorithm similar to the Down syndrome risk algorithm. Blood specimens are accepted if collected between 15 and 20 weeks gestation. Reports of all procedures performed and all diagnoses made are required. Special provisions have been adopted for twins, donated ova, family history of NTD, or exposure to certain teratogenic medications. NTDs and chromosomal disorders, however diagnosed, are classified as reportable disorders under State law.

\section{Expanded AFP Screening Program experience}

We report here the experience with the Expanded AFP Screening Program design (in which the Program sets standards and

Table 3

The California MSAFP and expanded AFP program utilization

\begin{tabular}{llccc}
\hline Year & Program & $\begin{array}{c}\text { Number of women } \\
\text { eligibles to participate } \\
\text { in the program }\end{array}$ & $\begin{array}{c}\text { Number of women } \\
\text { electing to participate } \\
\text { in the program }\end{array}$ & $\begin{array}{c}\text { Percent } \\
\text { program } \\
\text { utilization }\end{array}$ \\
\hline 1986 & AFP & 223,961 & 91,742 & 41.0 \\
1987 & AFP & 467,526 & 210,369 & 45.0 \\
1988 & AFP & 494,295 & 239,495 & 48.5 \\
1989 & AFP & 524,240 & 262,996 & 50.2 \\
1990 & AFP & 563,407 & 291,459 & 51.7 \\
1991 & AFP & 565,392 & 318,680 & 56.4 \\
1992 & AFP & 564,091 & 335,227 & 59.4 \\
1993 & AFP & 550,024 & 337,295 & 61.3 \\
1994 & AFP & 534,783 & 335,618 & 62.8 \\
1995 & AFP/XAFP & 520,879 & 340,832 & 65.4 \\
1996 & XAFP & 511,625 & 353,828 & 69.2 \\
1997 & XAFP & 511,521 & 356,157 & 69.6 \\
Total & AFP/XAFP & $6,031,743$ & $3,473,698$ & - \\
\hline${ }^{3}$ Eligibility: Pregnant women who are in prenatal care between the $15^{\text {th }}$ and the $20^{\text {th }}$ week of gestation.
\end{tabular}

July/August $1999 \cdot$ Vol. $1 \cdot$ No. 5 
Table 4

California Expanded AFP 95-97 utilization by age and race

\begin{tabular}{lccccr}
\hline Age group & Hispanic & White & Asian & Black & All Races" \\
\hline 34 years and younger & 362,050 & 237,576 & 60,220 & 49,584 & 770,576 \\
35 years and older & 27,528 & 26,769 & 8,192 & 4,013 & 71,929 \\
All ages & 391,872 & 265,642 & 68,937 & 53,937 & 848,083 \\
\hline
\end{tabular}

"Includes other and unknown race.

Table 5

California Expanded AFP 95-97 acceptance of amniocentesis

\begin{tabular}{lccccc}
\hline PDC.status & Hispanic & White & Asian & Black & All $^{*}$ \\
\hline Appointment kept & 19,676 & 12,931 & 4,407 & 3,394 & 43,073 \\
Confirmed screen positive & 12,900 & 10,794 & 3,503 & 2,554 & 31,738 \\
& $(65.6 \%)$ & $(83.5 \%)$ & $(79.5 \%)$ & $(75.3 \%)$ & $(73.7 \%)$ \\
Offered amniocentesis & 12,579 & 10,611 & 3,450 & 2,516 & 31,102 \\
& $(63.9 \%)$ & $(82.1 \%)$ & $(78.3 \%)$ & $(74.1 \%)$ & $(72.2 \%)$ \\
Accepted amniocentesis & 8,320 & 8,046 & 2,655 & 1,775 & 22,188 \\
& $(66.1 \%)$ & $(75.8 \%)$ & $(77.0 \%)$ & $(70.5 \%)$ & $(71.3 \%)$ \\
\hline
\end{tabular}

"Includes other and unknown race.

pays private providers for services in a coordinated statewide system). The period is from July 29, 1995 through December 31, 1997.

Acceptance of the test by pregnant women is voluntary. Women younger than 35 were offered triple marker screening. Women older than 35 were offered either direct referral for amniocentesis or blood testing. A separate consent form was used. There have been no special efforts to promote the Program with mass media or mailings to encourage women to participate in the Program. During the study period there were 1,256,377 eligible pregnancies, and 848,083 or $67.5 \%$ of the women elected to participate. Of the 1,082,637 eligible women younger than age $35,770,576$ (71\%) participated in screening, and of the 173,740 eligible women older than age $35,71,929(41.4 \%)$ were participants (Table
4). This reflects the fact that women older than 35 have the option to choose amniocentesis rather than serum screening. Participation by race/ethnicity was reasonably close to representation of the races in the eligible population. Nonparticipation could be due to a failure to offer the test, a cultural lack of understanding of prenatal detection of birth defects, a lack of confidence in a technology that gives only risks, objection to termination of pregnancy, or unwillingness or inability to pay. Limited studies have been performed to characterize this group of nonparticipants.

Of the women who consented to be tested, $96.4 \%$ were successfully screened; they received either a screen positive or screen negative test result. Failures occurred due to unsatisfactory specimens or specimens collected too early and never replaced by a satisfactory specimen. All participants were tracked by the

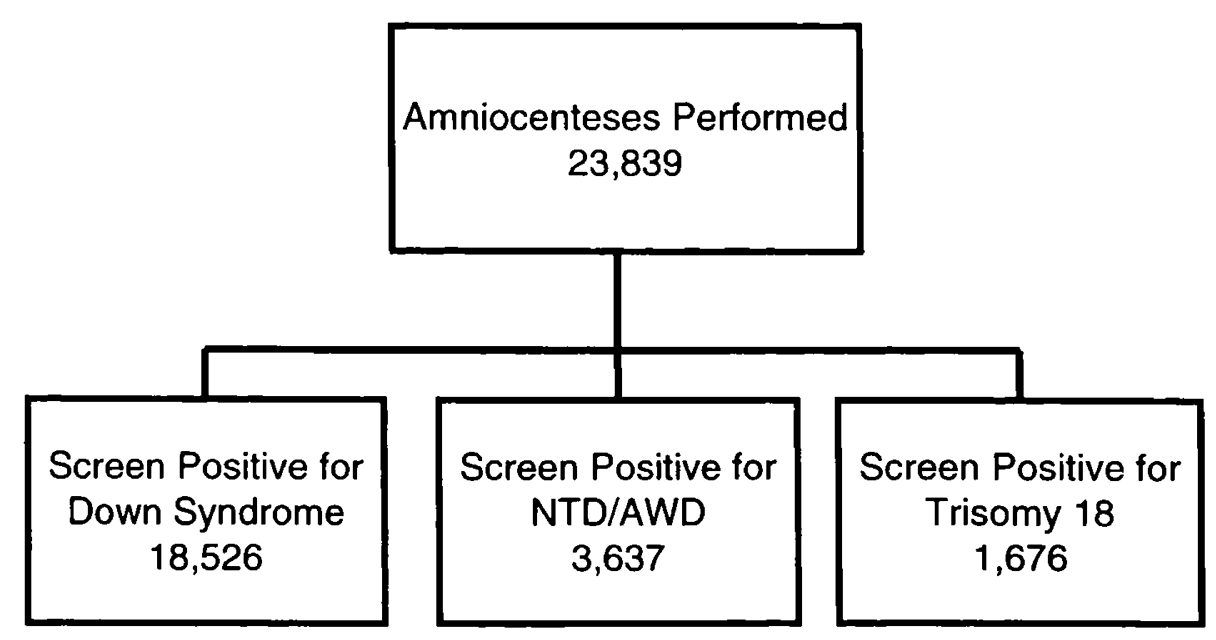

Fig. 2 Amniocenteses performed by indication in the California Expanded AFP Program between 1995 and 1997. 
central computer system. Screen positive results or other results needing follow-up were telecommunicated daily to 1 of 14 specially trained regional follow-up coordinator offices under contract with the Program. There were 60,245 or $7.1 \%$ initial positive results distributed as follows: $1.5 \%$ screen positive for NTD, 5.5\% screen positive for Down syndrome, and $0.33 \%$ positive for trisomy 18 .

Verification of interpretation factors with the prenatal care provider by the coordinators resulted in reclassification of some initial positives to negative, too early or too late for testing. All 47,858 verified screen positives were referred to PDCs for workup. However, $10 \%$ declined referral or failed to keep the appointment, and $90 \%$ were seen at the PDC. The program provided more than 43,000 genetic counseling services and more than 43,000 ultrasound examinations, and 22,188 women accepted amniocenteses (Table 5). Some women were positive for more than one condition or had more than one procedure, resulting in 23,839 amniocenteses procedures (Fig. 2). As a result of this PDC follow-up, the Program detected 532 NTD, 309 AWD, 570 Down syndrome cases, 133 trisomy 18 cases, and 410 other significant chromosomal defects. One measure of program effectiveness is the number of amniocenteses needed to detect a case. One case of Down syndrome was found for every 33 amniocenteses $(570 / 18,526)$ and one case of trisomy 18 for every 13 amniocenteses (133/1676). Some NTDs were determined by ultrasound and did not have amniocentesis performed. The ratio was 1 NTD detected for 24 amniocenteses. The overall rate was 23 birth defects per 10,000 women screened (Table 6).

To estimate the detection rate, the program estimated the number of defects expected in the screened population by applying age-specific risk figures for chromosome anomalies and birth prevalence figures for NTD and AWD. This was compared with cases actually found.

For Down syndrome screening, the detection rates were calculated for two age groups: 34 years of age and younger, and 35 years of age and older. Among the younger group of women and the older group of women, $33 \%$ and $52 \%$ of the expected cases of Down syndrome were detected, respectively. The reported detection rates for Down syndrome, based on a theoretical model that assumes that all screen positive women will complete the entire sequence of tests and procedures, is $51 \%$ for women 34 and younger and $85 \%$ for women 35 and older (with an overall rate of $62 \%$ ), with an amniocentesis rate of $5 \% .{ }^{10}$ In actual prac-

Table 6

California Expanded AFP 95-97 Program detection rates

\begin{tabular}{lccc}
\hline & $\begin{array}{c}\text { Number expected } \\
\text { in screened } \\
\text { population }\end{array}$ & $\begin{array}{c}\text { Number } \\
\text { detected }\end{array}$ & $\begin{array}{c}\text { Detection } \\
\text { rate }\end{array}$ \\
\hline Neural tube defect & 705 & 532 & $75 \%$ \\
Abdominal wall defect & 358 & 309 & $86 \%$ \\
Down syndrome & 1,375 & 570 & $41 \%$ \\
Trisomy 18 & 313 & 133 & $42 \%$ \\
Other chromosome & & 410 & \\
Total & & 1,954 & \\
\hline
\end{tabular}

tice, in which women can choose to opt out at any point in the offered sequence of diagnostic tests and procedures, the overall program detection rate for Down syndrome was $41 \%$, and the actual amniocentesis rate among women screened was $2.2 \%$. Likewise, detection of NTD at the Program cutoff (2.5 MSAFP MoM for singleton pregnancies) based on a receiver operator curve is theoretically $85 \%$ and in practice was $75 \%{ }^{11}$

\section{BENEFITS EVALUATION}

For evaluation purposes and to assess the benefits of the Program, NTD, AWD, and Down syndrome were selected as the major birth defects that the Program was designed to detect and prevent. However, it is clear that there are many additional secondary benefits that were not included in this analysis. Detection of other structural defects, other chromosomal defects, early detection of twins, fetal demise, intrauterine bleeding, improved pregnancy dating, and identification of pregnancies at high risk of fetal and neonatal death and prematurity are also significant benefits. The screening test also is an additional inducement for early prenatal care. An exhaustive cost benefit analysis might want to try to assign a dollar value to these beneficial aspects.

In the determination of the fiscal benefits of the Program, we reviewed the extensive literature on the cost of care for Down syndrome and the meager information on NTD. ${ }^{12-31}$ We developed estimates of $\$ 450,000$ as lifetime costs for Down syndrome and $\$ 300,000$ for spina bifida. These estimates were used in program planning in 1985. Fortunately, a detailed analysis of the cost of care for birth defects in California, funded by the California Birth Defects Monitoring Program, March of Dimes, and Agency for Health Care Policy Research, was published in the Blue Cross/Blue Shield Association Journal Inquiry. ${ }^{32}$ The study looked at incremental costs, i.e., costs over and above those normally associated with the average infant, child, or adult. They included direct medical costs, inpatient/outpatient care, longterm disability, and developmental services and special education. Lost productivity due to mortality and morbidity was included. Calculation of productivity was based on age-related average income for men and women. The authors did not include lost productivity of parents or private out-of-pocket costs such as transportation, home modifications, wheelchairs, and appliances, etc. They did not include family stress-related costs, such as divorce counseling for parents.

This cost of care study produced total lifetime care per case cost avoidance in 1988 dollars at a $5 \%$ discount (to adjust for inflation) of $\$ 258,000$ for spina bifida and $\$ 410,000$ for Down syndrome. These estimates need to be adjusted to 1996 dollars (Table 7). If cost savings are limited to cases terminated after prenatal detection, the total savings accomplished by the Program through detection of Down syndrome, NTD, and AWD was conservatively estimated as $\$ 185,604,684$ (Table 7 ). Because $23 \%$ of Down syndrome detected would have been lost due to spontaneous abortion, we only included $77 \%$ of terminations in our cost avoidance. Some may argue that, at the current rate of economic growth, a lower discount rate would be a better estimate for a public program. This would increase the cost 
Table 7

California Expanded AFP 95-97 cost avoidance

\begin{tabular}{|c|c|c|c|c|c|c|c|}
\hline Birth defect & $\begin{array}{c}1988 \text { Costs } \\
(5 \% \text { discount rate) }\end{array}$ & & $\begin{array}{c}\text { Adjust } \\
1988 \$ \text { to } 1996 \$\end{array}$ & & $\begin{array}{c}\text { Number cases } \\
\text { averted }\end{array}$ & & Costs avoided \\
\hline Spina bifida & $\$ 258,000$ & x & 1.338 & $x$ & 109 & $=$ & $\$ 37,627,236$ \\
\hline Down syndrome & $\$ 410,000$ & $x$ & 1.338 & $x$ & $257^{a}$ & $=$ & $\$ 140,985,060$ \\
\hline Anencephaly & $\$ 5,000$ & $x$ & 1.338 & $x$ & 224 & $=$ & $\$ 1,498,560$ \\
\hline Gastroschisis & $\$ 94,000$ & $x$ & 1.338 & x & 20 & $=$ & $\$ 2,515,440$ \\
\hline (Omphalocele & $\$ 159,000$ & $\times$ & 1.338 & $\times$ & 14 & $=$ & $\$ 2,978,388$ \\
\hline \multicolumn{5}{|c|}{ Total cost avoidance } & 624 & & $\$ 185,604,684$ \\
\hline
\end{tabular}

${ }^{a}$ Corrected for $23 \%$ miscarriages.

avoidance figure, which is sensitive to the discount rate. If a discount rate of $2 \%$ is used, the cost avoidance would be more than 446 million dollars.

This benefit needs to be compared with the Program costs. Because the State provides all materials and services, except the cost of blood collection, and because all expenditures are accounted for to the State Department of Finance, this provides a unique opportunity to assess the true costs of the Program. Costs such as printing and distribution of forms and educational brochures, videos, postage, information flow and data processing, proficiency testing, quality control, telephoning for follow-up, costs of fee collection, etc., are frequently omitted from the cost estimates of laboratory based screening. The State also operates an NTD registry and a chromosome abnormality registry, pays a pro rata assessment to support the Legislature, and incurs State administrative costs, which are included in the total Program costs.

The Program's expenses from July 1995 to December 1997 were $\$ 60,184,903$. We estimate that additional expenses to the total health-care system of drawing blood, completing test request forms, and arranging for follow-up incurred by prenatal care providers, was averaged as $\$ 10$ per woman screened. We include the costs of termination, which was not included in Program expenses, because the abortions at an average cost of $\$ 700$ would add to Program costs. Thus, the Program's net cost was $\$ 69,102,533$. The average cost of prevention of one of the listed birth defects was $\$ 110,741$. The cost benefit rate is $\$ 2.69$ or more (Table 8 ). At the $2 \%$ discount rate the benefit is $\$ 6.45$. This is consistent with previous cost benefit analyses of MSAFP pub-

Table 8

California Expanded AFP program 95-97 cost-benefit analysis

\begin{tabular}{lr}
\hline Program expenses & $\$ 60,184,903$ \\
Private expenses $(\$ 10 /$ test $)$ & $\$ 8,480,830$ \\
Termination cost $(\$ 700 / \mathrm{AB})$ & $\$ 4,36,800$ \\
Total cost & $\$ 69,102,533$ \\
Cost avoidance & $\$ 185,604,684$ \\
Cost-benefit ratio & $\$ 2.69$ \\
Cost per birth defect prevented & $\$ 110,741$ \\
Cost per birth defect detected & $\$ 35,365$ \\
\hline
\end{tabular}

lished in the literature. This result was achieved in a low prevalence area for NTD. The California Birth Defects Monitoring Program estimates the NTD rate in California as 0.9 per 1000 births and fetal deaths.

\section{DISCUSSION}

Replacement type analysis was not performed, i.e., the effect of replacing a lost pregnancy with a live birth sometime in the future. The changes would be in the direction of improving the cost benefit ratio, but the adjustment is minor. Some have objected to the application of cost benefit analyses to prenatal screening, arguing that only benefits in health status can be validly accepted as a benefit. They reject the concept of cost avoidance as a result of termination. However, if the objectors accept the current basic political construct in the U.S. that health-care is a commodity that is subject to market forces, they, as prudent buyers, must accept a market-based analysis. Clearly, the maximization of the economic benefits becomes a legitimate objective of any health intervention based upon the market model. On the other hand, if they argue that adequate health-care is a societal benefit and entitlement for all citizens, then there is no basis to restrict access to screening, which is wanted and is used to improve mental health and quality of life of the participants. The cost benefit equation loses much of its significance.

Moreover, if a cost benefit analysis for a screening program that limits the cost avoidance to direct health-care services is performed, the program may not be cost beneficial. In other words, if an HMO or health insurance program pays for screening, it is also paying to avert educational and other costs for which the third party payer for health services is not directly liable.

Tapin et al., ${ }^{16}$ after conducting a cost benefit analysis for the Group Health Cooperative of Puget Sound, concluded:

"It may be that the time has come to look more closely at cooperative rather than competitive solutions to some health-care problems. Russell has suggested that prevention usually has a price. However, this analysis shows that, in the case of MSAFP screening, the price is paid directly by the insurer, while society receives the net benefit. To the extent that insurers refuse to pay that price and cover screening, participation may drop and society stands to lose. Our conclusions firmly suggest that it would be to the advantage of states and health-care insurers to cooperate in the 


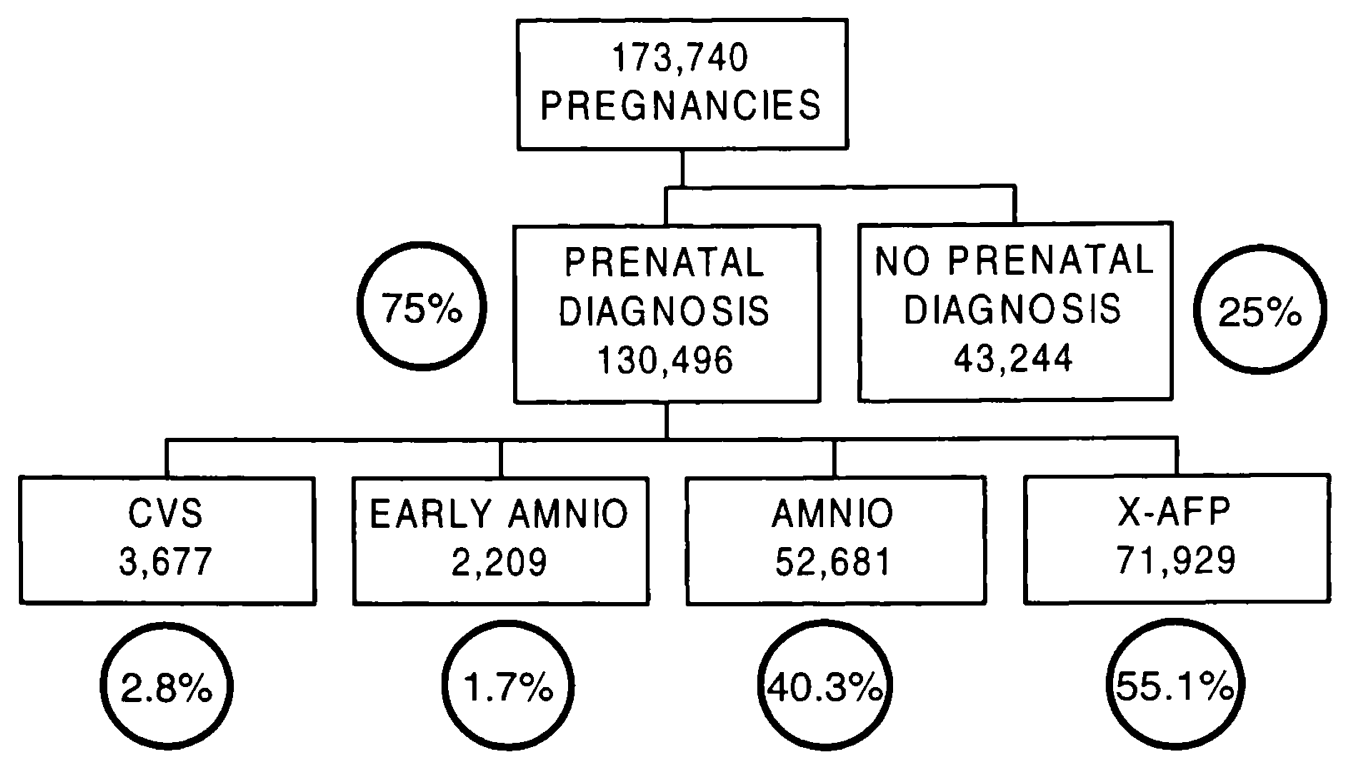

Fig. 3 Testing decisions and outcomes on 173,740 pregnancies in women 35 years and older, 1995-1997.

establishment of programs such as the one undertaken in California. Such cooperation would result in large programs, the economies of scale of which would reduce the two direct costs (the screening test and genetic amniocentesis) that have the greatest effect on the net cost of a screening program. Whether that would result in increased coverage and wider participation remains to be determined."

There has been some discussion about the ultimate effect of serum screening on Down syndrome detection in older women. This is an important consideration due to the increased trend toward older births. Of the 173,740 eligible women 35 and older during the study period, $75 \%$ elected to have either prenatal testing or diagnosis and $25 \%$ had no test at all (Fig. 3). Of the prenatally tested women, $44.9 \%$ elected to have some kind of invasive diagnostic procedure rather than the blood test, and $55.1 \%$ elected to have the triple marker test. Based on age-related risk for the 173,740 women, a total of 1,051 Down syndrome births were expected, and 794 or $75.5 \%$ were prenatally detected. Based on 515 terminations, after correction for spontaneous losses, we estimate that current prenatal screening practices in California resulted in a $49 \%$ reduction in birth prevalence in women older than 35. This is consistent with the estimates of Bishop et al. ${ }^{33}$

It is useful to reflect on the missed opportunities for avoidance of birth defects and the discrepancies of results in actual programs in comparison with the theoretical models or experience with small selective populations. The screening system cannot detect birth defects prenatally among the $5 \%$ of women who do not seek care before 20 weeks. This emphasizes the importance of promotion of free or low cost pregnancy testing and early referral for prenatal care. Once in care, the clinician must take the initiative to routinely and universally offer prenatal testing. Without the offer, avoidable cases will occur in the unscreened group. For each woman consenting to be screened, it is important to draw a timely blood specimen, taking appropriate precautions to prevent hemolysis, and get it promptly to the designated screening laboratory for analysis. It is critical to provide the best estimate of gestational age possible and the information needed to apply the adjustment factors. Errors in these steps can lose the window of opportunity to screen. The biology of the markers and the precision and accuracy of the quantitation of analytes are such that a number of affected fetuses do not have results in the screen positive range. Improved markers, improved assays, and modifications of screen positive cutoff levels can help reduce cases missed during screening. Prompt follow-up of screen positive results is important. Although California has 29 PDCs located in population centers and 90 satellite sites, there are still rural areas where access to follow-up is difficult to guarantee. In our program 10\% of all high-risk women offered follow-up did not appear for their PDC appointment. These women receive a letter encouraging them to use the "free" follow-up services. Considering the problems of language barriers of our multi-ethnic population, increasingly mobile society, and large numbers of illegal aliens, the fact that only $10 \%$ of these high risk women do not complete referral is remarkable. There is, however, a larger group of women who, after counseling and ultrasound scanning, elect not to have an amniocentesis, adding to the population of incompletely screened women. Twenty-five percent of whites and 33\% of Hispanics declined amniocentesis (Table 5). Although included in the initial positive rate, they are not included in the final detection rate. Finally, the impact of screening is in part determined by the termination rate. In contrast to reports in the literature of 70 $80 \%$ termination of Down syndrome, there is a significant number of women in California who elect not to terminate after a diagnosis is made. The overall termination rate of $58.6 \%$ for Down syndrome includes ethnocultural differences, because $66 \%$ of whites and only $48 \%$ of Hispanics elect to terminate 
Table 9

Callifornia Expanded AFP 95-97 decision for clective termination of pregnancy

\begin{tabular}{|c|c|c|c|c|c|c|c|c|c|c|}
\hline \multirow[b]{3}{*}{ Fetal Abnormulity } & \multicolumn{2}{|c|}{ Ilispanic } & \multicolumn{2}{|c|}{ White } & \multicolumn{2}{|c|}{ Asian } & \multicolumn{2}{|c|}{ Black } & \multicolumn{2}{|c|}{ Total } \\
\hline & No. & $11 / 1$ & No. & $\%$ & No. & $\%$ & No. & $\%$ & No. & $\%$ \\
\hline & I) $x$ & $\mathrm{TAB}$ & $1) x$ & $\mathrm{TAB}$ & DXX & $\mathrm{TAB}$ & $\mathrm{DX}$ & $\mathrm{TAB}$ & $\mathrm{DX}$ & $\mathrm{TAB}$ \\
\hline Anencephaly & 157 & 68.2 & 92 & 88.0 & 20) & 80.0 & 10 & 70.0 & 297 & 75.4 \\
\hline Spina bifida & 74 & 60.8 & 69 & 72.5 & 7 & 57.1 & 6 & 83.3 & 162 & 67.3 \\
\hline All neural tube detects & 254 & 6.5 .3 & 195 & 77.4 & 33 & 69.7 & 18 & 66.7 & 532 & 70.7 \\
\hline Ciastroschisis & 122 & 8.2 & 65 & 10.8 & 11 & 18.2 & 11 & 0.0 & 220 & 9.1 \\
\hline ()mphalocele & 19 & 26.3 & 16 & 18.8 & 2 & 50.0 & 3 & 33.3 & 45 & 31.1 \\
\hline All abdominal wall defects & 164 & 18.9 & 95 & 21.1 & 17 & 35.3 & 15 & 13.3 & 309 & 21.4 \\
\hline Down syndrome & 244 & 47.5 & 196 & 65.8 & 72 & 70.8 & 24 & 62.5 & 570 & 58.6 \\
\hline Trisomy 18 & $5 n$ & 55.4 & 45 & 73.3 & 16 & 68.8 & 6 & 50.0 & 133 & 66.2 \\
\hline All chromosome abnormalities & 443 & 44.7 & 401 & 56.1 & 138 & 57.2 & 60 & 40.0 & 1113 & 51.0 \\
\hline All abnormalities & 866 & 46.1 & 691 & 57.6 & 188 & 57.4 & 93 & 40.9 & 1954 & 51.8 \\
\hline
\end{tabular}

DX, prenatally detected; TAB, therapeutic abortion.

(Table 9). All of our cases received face-to-face counseling with a board certified counselor.

The case for state-administered screening has been stated. We hope you will agree that this model has achieved its overall objectives of providing universal access to low cost, high quality screening and follow-up.

\section{References}

1. Andrews LB, Fullarton IE, Holtzman NA, Motulsky AG. Assessing genetic risks: Implications for health and social policy, Washington, DC: National Academy Press, 1994.

2. Omenn CS. Genetics and public health. Am I Public Health 1996;86:1701-1704.

3. Khoury MJ. From genes to public health: The applications of genetic technology disease prevention. Am J Public Health 1996;86:1717-1722

4. Brock DIH, Bolton AE, Scrimgeour IB. Prenatal diagnosis of spina bifida and anencephaly through maternal plasma-alpha-fetoprotein measurement. Lancet 1974;i:767.

5. Second Report of the U.K. Collaborative Study on Alpha-fetoprotein in Relation to Neural Tube Defects. Amniotic Fluid Alpha-fetoprotein Measurement in Antenatal Diagnosis of Anencephaly and Open Spina Bifida in Early Pregnancy. Lancet 1979;ii:652.

6. Macri JN, Haddow IE, Weiss RR. Screening for neural tube defects in the united states. Am J Obstet Gynecol 1979:133:119-125.

7. Consensus Meeting Special Report. Maternal serum alpha-fetoprotein screening for neural tube defects. Prenat Diagn 1985;5:77-83.

8. American Society of Human Genetics. Policy Statement for a Maternal Serum Alpha Fetoprotein Screening Program. ASHG, Derwood, Maryland, November 2, 1986.

9. Cuckle HS, Wald NI, Thompson NI. Estimating a woman's risk of having a pregnancy associated with Down's syndrome using her age, and serum alpha-fetoprotein level. $B M /$ 1981:94:387-402.

10. Wald NJ, Cuckle HS, Densem IW, Nanchahal K, Royston P, Chard T, Haddow IE, Knight GI, Palomaki GE, Canick IA. Maternal sereening for Down's syndrome in carly pregnancy. BMJ 1988;297:883-887.

11. Estimating an individual's risk of having a fetus with open spina bifida and the value of repeat alpha-fetoprotcin testing. Fourth report of the United Kingdom Collaborative Study on Alpha-Fetoprotein in Relation to Neural Tube Defects. I Epidemiol Commun Health 1982;36:87-95.

12. Glass N. Economic aspects of the prevention of Down's syndrome (Mongolism). In Bailey NTI, Thompson M, editors. Systems aspects of health planning. Amsterdam: North-Holland, 1975;725-732.

13. Hagard S, Carter F. Preventing the hirth of infants with Down's syndrome. A cost benefit analysis. BMJ 1976;27:753-756.

14. Mikkelsen M, Nielsen G. Cost benefit analysis of prevention of Down's syndrome. In Boue A, editor. Les Colloques de l'Institut National de la Santé ct de la Recherche Médicale. Prenatal Diagnosis. Paris: INSERM, 1976:61:283-289.

15. Shackley P, McGuire A, Boyd PA, Dennis I, Fitchett M, Kay I, Roche M, Wood P. An economic appraisal of alternative pre-natal screening programmes for Down's syn- drome I Public Health Afd 1993:15:175-184

16. Tapin SH, Thompson RS, Conrad DA. Cost justification analysis of prenatal serum alpha feto-protein screening. Mid Carc 1988:26:1185-1202.

17. Williamson R. Improved screening for fetal chromosome abnormalities. Iowa Med 1990:80:125-128.

18. Sheldon TA, Simpson J. Appraisal of a new scheme for prenatal screening for Down's syndrome. BM/1991;302:1133-1136.

19. Sadovnick AD, Baird PA. A cost benefit analysis of prenatal detection of Down syndrome and neural tube defects in older mothers. Am / Med Genet 1981;10:367-378.

20. Goldstein H, Philip I, Dupont A. One year of health and social services for children 3-7 years old with Down syndrome. Soc Psychiatry 1986:21:134-138.

21. Campbell TL. Maternal serum alpha feto-protein screening: Benefits, risks and costs. I Fom Pract 1987:25:461-467.

22. Layde PM, von Allmen SD, Oakley GP Ir. Maternal serum alpha-fetoprotein screening: a cost-benetit analysis. Am J Public Health 1979;69:566-573.

23. Gill M, Murday V, Slack I. An economic appraisal of screening for Down's syndrome in pregnancy using maternal age, and serum alpha fetoprotein concentration. $\mathrm{Sec} S \mathrm{Si}$ Med 1987;24:725-731

24. Edel CM, Edel M. Economic costs of aneuploidy: Some problems of measurement and conceptualization. In: Dellarco VL, Voylek PE, editors. Aneuploidy etiology and mechanisms. New York: Plenum Press, 1985;61-73.

25. Braddock D, Hemp R, Howes R. Direct costs of institutional care in the United States. Mcntal Retard 1986;24:9-17

2h. Ginsberg G. Costs of caring for spina bifida and Down syndrome. Unpublished report State of New York, Department of Health, 1987.

27. Seror V, Moatti IP, Muller F, Le Gales C. Boue A. Cost-benefit analysis of prenatal screening for trisomy 21 through analysis of $\mathrm{HCG}$ in maternal blood. Rev Epidemiologic Santi Publiquic 1993;11:3-15.

28. Seror V, Muller F, Moatti IP, Le Gales C, Boue A. Economic assessment of maternal serum screening for Down's syndrome using human chorionic gonadotropin. Prenat Diagn 1993:13:281-292

29. Conley RW. Down syndrome: Economic burdens and benefits of prevention. In: Dellario VL, Voylek PE, editors. Aneuploidy etiology and mechanisms. New York Plenum Press, 1985:35-57

30. Hook EB. Genetic counseling and prenatal cytogenetic services: Policy implications and detailed cost benefit analysis of program for the prevention of Down syndrome. In: Porter IH, Hook EB, eds. Birth defects institute, symposia, service and education in medical genetics. New York: Academic Press, 1979;29-54.

31. Hook EB, Chambers GM. Estimated rates of Down syndrome in live births by one year maternal age intervals for mothers aged $20-49$ in New York State study. Implications of the risk figures for genetic counseling and cost benefit analysis of prenatal diagnosis programs. Birth Defect Original Article Series, Vol XIII, No. 3A; 1977:123-141.

32. Waitzman NI, Romano PS, Scheffler RM. Estimates of the costs of birth defects. Inquiry 1994;33:188-205.

33. Bishop I, Huether CA. Tofts C, Lorcy F, Deddens J. Epidemiologic study of Down syndrome in a racially diverse california population. 1989-1994. Am J Epidemiol 1997;145:134-147. 